\title{
User Interface Design Challenges for Digital Libraries
}

\author{
Hanumat G. Sastry \\ Department of Computer Science, \\ School of Science \& Technology, \\ Dravidian University, Kuppam, \\ Andhra Pradesh, India.
}

\author{
Manjunath.G. \\ Department of Computer Science \& \\ Engineering, \\ Jawaharlal Institute of Technology, \\ Hyderabad, Andhra Pradesh, India.
}

\author{
Dr. Lokanatha C. Reddy \\ Department of Computer Science, \\ School of Science \& Technology, \\ Dravidian University, Kuppam, \\ Andhra Pradesh, India.
}

\begin{abstract}
Digital Libraries are evolving rapidly with the usage of Internet and WWW technologies. Since the digital libraries are running on the Internet and the users are from various psychological, educational and social backgrounds, the usage of digital libraries is varying from user to user which entail the need of best user interface. In order to design usable and useful interactive systems, designers need to ensure that good design features are incorporated into the systems, taking into consideration end-users' needs, experience and cultural backgrounds [1]. Hence, this paper presents the users' study in various aspects and identifies various challenges for designing the user interface system for university digital libraries for its effective implementation.
\end{abstract}

\section{Keywords}

Digital Libraries, Human-Computer Interaction, User Interfaces, User Interface Challenges.

\section{INTRODUCTION}

All knowledge of humanity is preserved in the form of hard material and is spread over across the globe. The first libraries, as such, arose in the ancient civilization of Mesopotamia for the preservation of administrative records [2]. Libraries play a significant role in promotion of culture and education with its key functions. The key functions of libraries are knowledge archival, preservation and maintenance of culture, knowledge dissemination, knowledge sharing, information retrieval, education, and social interaction [3]. Hitherto knowledge was accessible through Libraries of various statures and also through personal subscriptions to knowledge bases in the form of magazines and journals. . These tasks are, however, not trivial to accomplish: many libraries are rapidly growing out of storage space as the amount of publications keeps increasing; some editions may not be available at the local library; and old documents may be all but impossible to obtain. It is a natural quest to make this knowledge accessible at any corner on earth in the present day technology scenario.

The Internet and the World Wide Web (WWW) technologies are providing the technological environment and intellectual impetus for the development of 'Digital Libraries' - libraries without walls, with contain less data and more ideas.

Digital libraries are disseminating the knowledge globally by breaking the physical barriers. Digital libraries are truly a technology for the masses, which plays a vital role in sharing of knowledge and culture. The fundamental reason for building the digital libraries is to disseminate the better information in most convenient way which was not possible earlier [4]. Huge sum of money has been spent on building the digital libraries, however research has shown that digital libraries are under utilized, due to their infancy user interfaces [5][6][7] and information overload. User satisfaction is a key to quality in digital library services [8], the user interface system, has gained much deliberation due to the fact that it affects the usability, which is a key factor for the success of the digital library system. Digital libraries are intrinsically interactive systems, which are not a specific collection, or an organization of collections, but are instead a unified means for a user to access the full range of information and services on the local and global network. Hence, it varies from the traditional workstation environments that shaped current graphical user interface (GUI) technologies. Designing the effective user interface system for digital library needs to understand the larger context that determines the users' information, needs and purposes for using the DL, that is, the context of the users' work; the individual user's specific work and tasks. Userstudies are necessary not only for planning and designing information systems but also for their efficient and effective operation. Hence, this paper presents the users' study in various aspects and identifies various challenges for designing the user interface system for digital libraries for its effective implementation in universities. This paper is organized as follows section 2 presents the literature review section 3 presents adopted methodology for studying the users section 4 presents the study findings section 5 presents the identified user interface challenges for digital libraries and finally conclusion follows.

\section{LITERATURE REVIEW}

The information needs of individuals have long been studied by researchers in marketing, education, and information science. There is a long history of studies of what types of information needs people bring to libraries [9] [10] [11] [12]. Information science researches recognize that there are different levels of information needs like specified visceral, conscious, formalized, and compromised levels [13].

That individuals vary on a host of physical, mental, and emotional characteristics is a defining condition of humanity [14]. Much of psychology is devoted to identifying the essential dimensions of human behavior [15] [16]. Designing the user interface for universal access is more complex than designing for specific populations because the entire range of human characteristics and needs must be supported. Thus, assessing needs and designing User Interface System for digital libraries in Indian Universities require systematic examination 
of many communities and will likely to lead to multiple system solutions.

In general the users of the digital libraries can be grouped into practitioners, teachers, students, researchers, counselors, policymakers, parents and administrators and most of the users access the digital libraries for research reports, project descriptions, position papers, evaluative reports, literature, teaching guides, books and conference papers [17].

We conducted a study to identify the potential groups of contemporary users or stakeholders and their requirements in Indian University Digital Libraries for designing the better user interface system.

\section{ADOPTED METHODOLOGY}

The studies have conducted with a broad approach based on common industry specifications and other standard research works, using a variety of research methods including surveys, participant observation, usability testing, ethnographic studies, focus groups and transaction log analysis.

Surveys and questionnaires represent one of the most inexpensive and easiest methods of collecting user opinions and attributes [18]. The survey has been conducted through email and personal data collection mode. Questionnaire has formulated based on the Question for User Interface Satisfaction (QUIS) [19] and other standard research works that are relevant to the digital libraries. Questionnaire has been sent to various persons in various capacities in selected Indian universities and higher learning institutions of different kind. The specific research questions include.

- $\quad$ Age and Gender

- Academic Qualifications

- Type of the Stakeholder

- $\quad$ Skills in Computer Usage and Computer Ownership

- Type of Information

- Information searching behavior and methodologies

- Internet access at home

- The frequency of Internet usage

- $\quad$ The length of Internet usage

- Internet skills

- Experience in creation and sharing of digital content

- Experience in usage of contemporary websites developed on Web 2.0 technologies

- $\quad$ Experience in usage of digital libraries

\section{FINDINGS OF THE USERS' STUDY}

We received $67 \%$ (335) of responses among 500 users. Among the received responses $42 \%$ (141) are female and $58 \%$ (194) are male. 5\% (17) are below 20,15\%(50) are between 20-25, $35 \%$ (117) are between $25-35,23 \%$ (77) are between $35-45$, $19 \%$ (64) are between $45-60$ and 3\% (10) are above 60. The table1 shows the profile of the respondents in terms of age, gender.

Table 1: Demography of Respondents Surveyed $(n=335)$

\begin{tabular}{|c|l|}
\hline \multicolumn{2}{|l|}{ Gender } \\
\hline Female & $42 \%$ \\
\hline Male & $58 \%$ \\
\hline Age & $5 \%$ \\
\hline Below 20
\end{tabular}

\begin{tabular}{|l|l|}
\hline $20-25$ & $15 \%$ \\
\hline $25-35$ & $35 \%$ \\
\hline $35-45$ & $23 \%$ \\
\hline $45-60$ & $19 \%$ \\
\hline 60 and above & $3 \%$ \\
\hline
\end{tabular}

The majority of the respondents are Post graduates i.e. $55 \%$ (184), M.Phil/Ph.D holders are 25\% (84) and under graduates or pursuing under graduates are 20\% (67). Most of the respondents are Research Scholars those are pursuing either Ph.D or M.Phil i.e. 35\% (117), 15\% (50) are academic assistants/teaching assistants, 10\% (35) are Lectures/Assistant Professors and Readers/Associate Professors, 5\% (17) are Professors, 10\% (34) are Research Fellows, 17\% (57) are Postgraduate Students and 3\% (10) are Undergraduate students. The respondents belong to various faculties like Engineering/Technology 40\% (134), Sciences 30\% (101), Humanities 28\% (94), and others 2\% (6).

Table 2: Academic Qualifications of Respondents Surveyed $(\mathbf{n}=\mathbf{3 3 5})$

\begin{tabular}{|c|c|}
\hline Academic Qualifications \\
\hline M.Phil/Ph.D holders & $25 \%$ \\
\hline Postgraduates & $55 \%$ \\
\hline Undergraduates & $20 \%$ \\
\hline
\end{tabular}

Table 3: Positions of Respondents Surveyed $(n=335)$

\begin{tabular}{|l|l|}
\hline \multicolumn{2}{|l|}{ Students } \\
\hline Research Scholars & $35 \%$ \\
\hline Postgraduate Students & $17 \%$ \\
\hline Undergraduate Students & $3 \%$ \\
\hline Faculty & $10 \%$ \\
\hline $\begin{array}{l}\text { Academic } \\
\text { Assistants/Teaching } \\
\text { Assistants }\end{array}$ & \\
\hline Lecturers/Assistant Professors & $15 \%$ \\
\hline Readers/Associate Professors & $5 \%$ \\
\hline Research Fellows & $10 \%$ \\
\hline Professors & $5 \%$ \\
\hline
\end{tabular}

Table 4: Faculties of Respondents Surveyed $(n=335)$

\begin{tabular}{|l|l|}
\hline Faculties \\
\hline Engineering/Technology & $40 \%$ \\
\hline Sciences & $30 \%$ \\
\hline Arts \& Humanities & $28 \%$ \\
\hline Others & $2 \%$ \\
\hline
\end{tabular}

We observed that the respondents are using the Internet for mailing, downloading music, instant messaging, social networking, online banking, online shopping, knowledge and information seeking. Very few respondents only reported that they have not accessed the Internet so far. In terms of usage of the Internet $30 \%$ (101) respondents are having novice experience, $40 \%$ (134) are having moderate experience and $28 \%$ (94) are having skillful experience. Most of the respondents are the users of the social networking sites and they have been influenced by rich user interactions and contemporary technologies. The following table depicts reasons and frequency of using the Internet by the respondents. 
Table 5: Reasons for and Frequency of Browsing the Internet $(\mathbf{n}=\mathbf{3 3 5})$

\begin{tabular}{|c|c|c|c|c|}
\hline \multirow{2}{*}{ Reasons } & \multicolumn{4}{|c|}{ Frequency } \\
\hline & Always & Seldom & Occasionally & Never \\
\hline E-mail & $46 \%$ & $39 \%$ & $13.50 \%$ & $1.50 \%$ \\
\hline Chatting & $24 \%$ & $48 \%$ & $26 \%$ & $2 \%$ \\
\hline $\begin{array}{l}\text { Music } \\
\text { Download }\end{array}$ & $8 \%$ & $15 \%$ & $50 \%$ & $27 \%$ \\
\hline $\begin{array}{l}\text { Images } \\
\text { Download }\end{array}$ & $2.40 \%$ & $27.30 \%$ & $40.60 \%$ & $29.70 \%$ \\
\hline $\begin{array}{l}\text { Software } \\
\text { Download }\end{array}$ & $5 \%$ & $11.30 \%$ & $25 \%$ & $58.70 \%$ \\
\hline $\begin{array}{l}\text { Playing } \\
\text { games }\end{array}$ & $5 \%$ & $15 \%$ & $32 \%$ & $48 \%$ \\
\hline $\begin{array}{l}\text { Using } \\
\text { search } \\
\text { engines }\end{array}$ & $42 \%$ & $37 \%$ & $20 \%$ & $1 \%$ \\
\hline $\begin{array}{l}\text { Browsing } \\
\text { for general } \\
\text { information }\end{array}$ & $45 \%$ & $27 \%$ & $26 \%$ & $2.50 \%$ \\
\hline $\begin{array}{l}\text { Accessing } \\
\text { digital } \\
\text { libraries } \\
\end{array}$ & $25 \%$ & $40 \%$ & $25 \%$ & $10 \%$ \\
\hline $\begin{array}{l}\text { Browsing } \\
\text { for } \\
\text { advanced/ } \\
\text { research } \\
\text { oriented } \\
\text { information }\end{array}$ & $30 \%$ & $20 \%$ & $10 \%$ & $40 \%$ \\
\hline $\begin{array}{l}\text { Online } \\
\text { shopping }\end{array}$ & $12 \%$ & $28 \%$ & $10 \%$ & $50 \%$ \\
\hline $\begin{array}{l}\text { Online } \\
\text { banking }\end{array}$ & $14 \%$ & $30 \%$ & $15 \%$ & $41 \%$ \\
\hline $\begin{array}{l}\text { Creating } \\
\text { web pages }\end{array}$ & $6 \%$ & $13.30 \%$ & $22 \%$ & $58.70 \%$ \\
\hline $\begin{array}{l}\text { Digital } \\
\text { content } \\
\text { creation and } \\
\text { sharing }\end{array}$ & $10 \%$ & $11.30 \%$ & $21 \%$ & $57.70 \%$ \\
\hline $\begin{array}{l}\text { Using the } \\
\text { wikis }\end{array}$ & $45 \%$ & $27 \%$ & $26 \%$ & $2.50 \%$ \\
\hline $\begin{array}{l}\text { Using the } \\
\text { blogs }\end{array}$ & $45 \%$ & $27 \%$ & $26 \%$ & $2.50 \%$ \\
\hline $\begin{array}{l}\text { Instant } \\
\text { Messaging }\end{array}$ & $24 \%$ & $48 \%$ & $26 \%$ & $2 \%$ \\
\hline $\begin{array}{l}\text { News } \\
\text { groups }\end{array}$ & $30 \%$ & $20 \%$ & $20 \%$ & $30 \%$ \\
\hline $\begin{array}{l}\text { Multimedia } \\
\text { sharing }\end{array}$ & $20 \%$ & $50 \%$ & $25 \%$ & $5 \%$ \\
\hline $\begin{array}{l}\text { Social } \\
\text { networking }\end{array}$ & $35 \%$ & $32 \%$ & $28 \%$ & $5 \%$ \\
\hline Others & $13 \%$ & $15 \%$ & $52 \%$ & $20 \%$ \\
\hline
\end{tabular}

We observed that most of the Indian universities and higher learning institution libraries are automated but not digitalized; very few universities have established the digital libraries. Among them $48 \%$ of the institutions are using DSpace digital repository software, $33 \%$ of the institutions are using Greenstone digital library software, $16 \%$ of the institutions are using either EPrints or Fedora Digital library Software and only
$3 \%$ are using other software systems including custom/proprietary build for building the institutional digital libraries. This study further identified most of the digital libraries are build upon the open source software systems with their core architectural paradigm without providing any enhancements.

We identified the potential groups of digital library users in Indian universities based on computer usage skills as Expert, Moderate and Novice users. And each potential group is further classified based on their role as Professors, Research Fellows, Teachers, Academic Consultants, Research Scholars, PostGraduate Students, Under-Graduate Students and Visitors. The following diagram depicts the potential user groups of digital libraries in Indian universities.

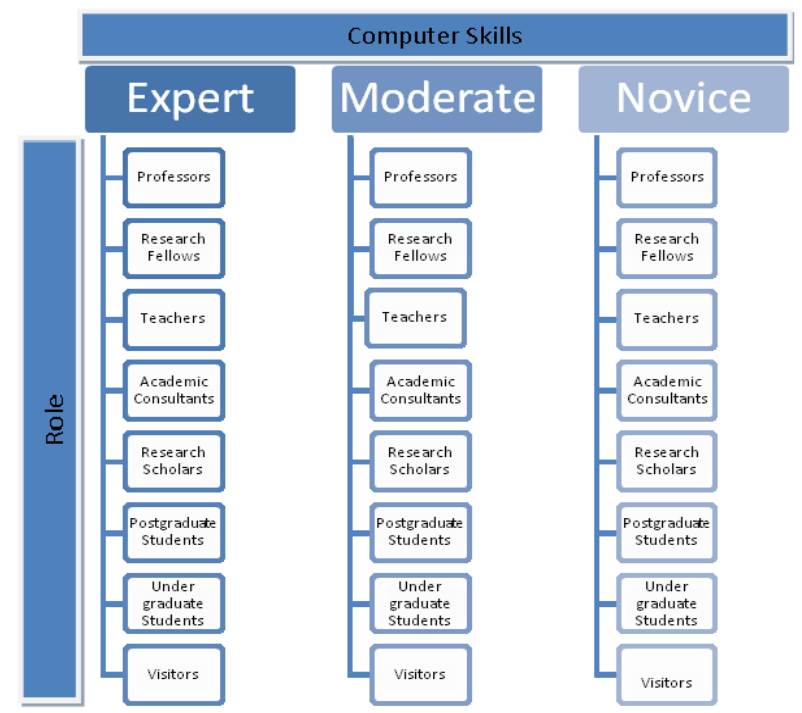

Figure 1: Potential User groups of digital libraries in Indian Universities

We observed the following primary purposes of using the library by the various user groups in Indian universities.

Table 6: User Groups-Primary Purposes of Visiting Library

\begin{tabular}{|c|c|}
\hline User Group & $\begin{array}{l}\begin{array}{l}\text { Primary purposes of } \\
\text { (sequential order) }\end{array} \\
\end{array}$ \\
\hline $\begin{array}{l}\text { Students } \\
\text { (including } \\
\text { PG and UG) }\end{array}$ & $\begin{array}{l}\text { - For notes preparation by using prescribed } \\
\text { texts } \\
\text { - General reading }\end{array}$ \\
\hline $\begin{array}{l}\text { Research } \\
\text { Scholars }\end{array}$ & $\begin{array}{l}\text { - For research journal, technical and term } \\
\text { papers } \\
\text { - Preparing for Teaching by referring the } \\
\text { prescribed books } \\
\text { - Reading of some advanced level books } \\
\text { - General reading }\end{array}$ \\
\hline $\begin{array}{l}\text { Teaching } \\
\text { Faculty }\end{array}$ & $\begin{array}{l}\text { - For teaching preparation by referring } \\
\text { prescribed texts } \\
\text { - Gathering additional information for teaching } \\
\text { from other than the prescribed texts } \\
\text { - Reading of research oriented books } \\
\text { - General reading }\end{array}$ \\
\hline Rese & - For research journals, technical \\
\hline
\end{tabular}




\begin{tabular}{|c|c|}
\hline Fellows & $\begin{array}{l}\text { papers } \\
\text { - Reading of advanced level research oriented } \\
\text { books } \\
\text { - General Reading }\end{array}$ \\
\hline Professors & $\begin{array}{l}\text { - For research journals, technical and term } \\
\text { papers } \\
\text { - Reading of advanced level research oriented } \\
\text { books. } \\
\text { - Teaching preparation by referring some } \\
\text { advanced level texts } \\
\text { - General Reading }\end{array}$ \\
\hline
\end{tabular}

The following user activities/goals are identified in using of the digital libraries in both real time and test bed environments.

- Information Discovery: This is the primary activity of all groups of digital library users. Users discover the information in a way of searching and browsing the digital library according to their need.

- Information Access: After successful discovery of information by using either searching or browsing, user access the information either for reading or for printing.

- Information personalization: User wants some set of personalization features while accessing the digital libraries. Search results storing and filtering, bookmarking the information are some of the goals.

- Information Creation: Users can create new information and deposit into the digital library.

- Information Review/Comment: Existing information can be reviewed by the user and he comments the information.

- Information Sharing: User shares the discovered search results, information with other likely interested people in order to enrich the rich the knowledge.

Further we observed the following related to user interests in using of the user interface system.

- Users prefer to use the well designed high resolution screens with standard colors.

- Users prefer to use standard icons which are familiar to them.

- Users prefer to read the content with high intensity of foreground and plain light colored background.

- Users prefer to read the text with proper alignment and spacing.

- Users prefer to use navigation links placed on the left side of the screen comparative with other sides of the screen.

- Users prefer to use the standard menus comparative with the other types of menu styles.

- Users prefer to use the Search Pan placed on the top right of the screen comparative with other sides of the screen

- Users prefer to use Submit and Cancel buttons placed Submit button fist and Cancel button next with the placement of the right side bottom of the screen.
- Users prefer to use simple and quick response screens.

We observed that presently Indian university digital libraries are comfortable for expert users that to faculties of Science and Engineering/Technology only. Most of the users from faculties of Arts and Humanities and the users with moderate and novice computer knowledge are not using the digital libraries due to either lack of content or the hindrances in using of infancy user interface of the digital library system.

\section{USER INTERFACE DESIGN CHALLENGES FOR UNIVERSITY DIGITAL LIBRARIES}

After careful analysis of users' study we identified the following user interface challenges of digital libraries which are to be addressed in designing of the user interface system in order to increase digital library access in universities.

\section{User oriented challenges}

- The characteristics of the users like social, psychological and cultural backgrounds etc...

- User's Intensions, Skill sets and Experiences

- The conceptual framework presented to the user

- The roll of feedback

- Operational characteristics command language, displays, responses, etc...

- $\quad$ Personalization of users

- User experience with other contemporary systems.

- $\quad$ The task to be performed

- Unexpected or Anonymous user behavior

Search oriented challenges

- The constraints of the computer IR techniques

- The effect of the IR system on the user interface for search

- $\quad$ Natural language queries for searching

- Context of the user for searching

- Handling misspelled and multiple forms of keywords

- $\quad$ Search facilities to the user

- Image/Multimedia object searching

- Collaborative search results

Content oriented challenges

- Multimedia content

- Multimodal interaction

- Multilingual content

Network oriented challenges

- Network speed

- Distributed systems

\section{CONCLUSION}

The above users study strongly demands the integration of contemporary technologies like Web 2.0 and Semantic Web technologies for building effective and usable digital libraries. The integration of user studies, user-centered design patterns with contemporary technologies in designing of the user 
interface systems for digital libraries would defiantly increase its usability. The above users study and the identified user interface design challenges would definitely helpful in

\section{REFERENCES}

[1] Yin Leng Theng, Elke Duncker, Norliza Mohd-Nasir, George Buchanan and Harold Thimbleby. 1999. Design Guidelines and User-Centred Digital Libraries. In Proceedings of the Third European Conference on Digital Libraries (ECDL 99).

[2] Sampson, G. 1985. Writing Systems. Stanford: Stanford University Press.

[3] Neal, S. 1997. The Virtual Library - a market perspective. The Bottom Line: Managing Library Finances, 10(3).

[4] Arms, W.Y. 2000. Digital Libraries. Cambridge: MIT Press.

[5] Hong W, Thong J.Y.L, Tam K.Y. 2002. Understanding user acceptance of digital libraries: What are the roles of interface characteristics, organizational context, and individual differences?. International Journal of Human-Computer Studies.

[6] Blandford, A., Stelmaszewska, H. 2001. Shooting the information rapids. In Vanderdonckt, landford, A., Derycke (eds.) IHM-HCI2001, Vol. II (short paper).

[7] Borgman, C. 2000. From Gutenberg to the global information infrastructure. The MIT Press.

[8] Selenay Aytac. 2003. Development of A User-Centered Digital Library for Ottoman Manuscripts. $24^{\text {th }}$ IATUL Conference Proceedings. Available at: www.iatul.org/doclibrary/public/Conf_Proceedings/.../ AYTAC_fulltext.pdf

[9] Paisley, W. 1980. Information work. Progress in Communication Sciences, Vol 2(113-165).

[10] Wilson, T. 1981. On user studies and information needs. Journal of Documentation, 37(1), 3-15.

\section{AUTHORS PROFILE}

Hanumat G. Sastry received his Masters' Degree in Computer Science from Vinayaka Missions' University, India. He is presently pursuing his $\mathrm{Ph} . \mathrm{D}$ in Computer Science, Dravidian University, India. His area of interest includes databases, digital libraries, user interfaces, e-commerce and web technologies.

Manjunath.G received his M.Tech (CS\&E) from Acharya Nagarjuna Univerisity, India. Presently, he is as an Associate Professor in Department of Computer Science and Engineering, Jawaharlal Nehru Institute of Technology -Hyderabad, India. He is working towards Ph.D degree in CS\&E. designing the effective user interface system for digital libraries.

[11] Krikelas, J. 1983. Information-seeking behavior: Patterns and concepts. Drexel Library Quarterly, 19(11), 5-20.

[12] Marchant, M. 1991. What motivates adult users of public libraries?. Library and Information Science Research, 13(3), 201-235.

[13] Taylor, R. 1962 (Oct). The process of asking questions. American Documentation, 391-397.

[14] Gary Marchionini, Catherine Plaisant, and Anita Komlodi. 2003. The People in Digital Libraries: Multifaceted Approaches to Assessing Needs and Impact. Available at http://citeseerx.ist.psu.edu/viewdoc/summary?doi=10.1. 1.64.2972

[15] Gardner, H. 1983. Frames of mind: The theory of multiple intelligence. New York: Basic Books.

[16] Sternberg, R. 1985. Beyond IQ: A triarchic theory of human intelligence. New York: Cambridge U. Press.

[17] Jolanta Mizera-Pietraszko. 2007. Model Design of User Interfaces for Multilingual Digital Libraries. TCDL Bulletin Vol 3 Issue 3. Available at: http://www.ieeetcdl.org/Bulletin/current/mizera-pietraszko/mizerapietraszko.html

[18] Karat, J. 1997. User-Centered Software Evaluation Methodologies. In M. Helander, T. K. Landauer, \& P. Prabhu (Eds.), Handbook of Human-Computer Interaction, Second Edition, . Amsterdam: Elsevier Science.

[19] Chin, J.P. Diehl, V.A. and Norman, K.L. 1988. Development of an instrument measuring user satisfaction of the human-computer interface. $\mathrm{CHI} 88$ Proceedings.

Dr. Lokanatha C. Reddy earned M.Sc. (Maths) from Indian Institute of Technology, New Delhi; M.Tech (CS) with Honours from Indian Statistical Institute, Kolkata; and Ph.D (CS) from Sri Krishnadevaraya University, Anantapur. Earlier worked at KSRM College of Engineering, Kadapa (1982-87); Indian Space Research Organization (ISAC) at Bangalore(1987-90). Head of the Computer Centre at the Sri Krishnadevaraya University, Anantapur; Presently, he is the Professor of Computer Science at the Dravidian University, Kuppam. His active research interests include Realtime Computation, Distributed Computation, Device Drivers, Geometric Designs and Shapes, Digital Image Processing, Pattern Recognition and Networks. 


\section{APPENDIX}

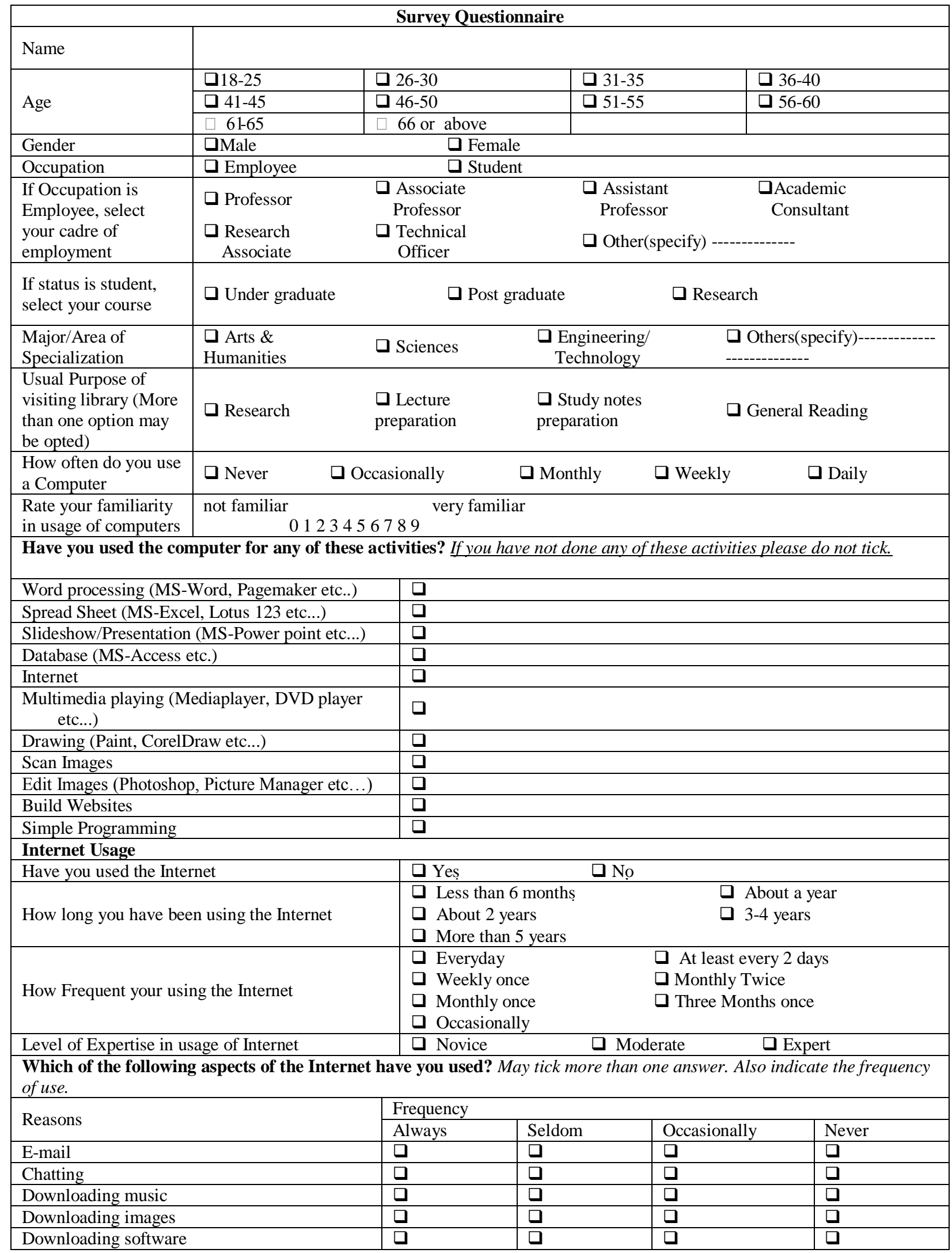




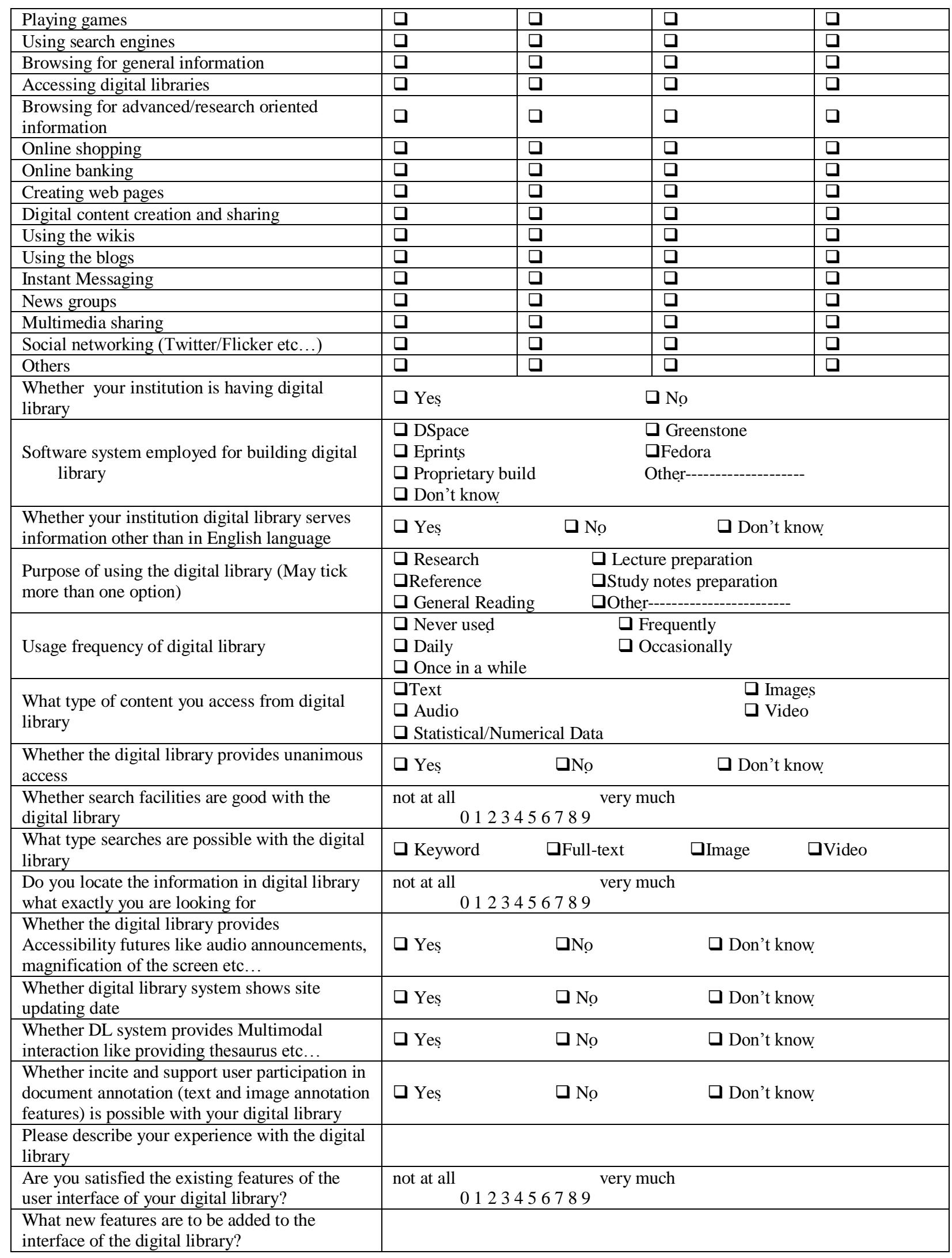

